\title{
ECTOPIC OSSIFICATION IN TUBERCULOUS MENINGITIS
}

\author{
BY \\ JOHN LORBER \\ From the Department of Child Health, University of Sheffield
}

(RECEIVED FOR PLBLICATION NOVEMBER 3, 1952)

The syndrome of severe wasting, opisthotonus and paraplegia in flexion associated with considerable hydrocephalus is well known to those treating advanced cases of tuberculous meningitis. Once such a condition has developed, the outlook is generally poor. Many patients will die and the survivors will often be handicapped by a variety of physical and mental sequelae.

The purpose of this paper is to describe and discuss a serious complication of tuberculous meningitis which does not seem to have been described before. This consists of ectopic ossification. It only occurred in children with spinal block and paraplegia. During 1950 and 1951 the Tuberculous Meningitis Unit of the Department of Child Health in Sheffield admitted 10 children who developed paraplegia and survived for a minimum period of three months. Ectopic ossification was observed in five of these 10 children, four of whom survived and are alive 16 to 33 months after the onset of meningitis.

\section{Case Histories}

In the first patient ectopic ossification was an accidental discovery. A 2-year-old boy had been unconscious for several weeks when gradually increasing difficulty was experienced in flexing him adequately for lumbar punctures. After he regained consciousness the hips were noted to be very stiff. The left thigh was held in flexion, adduction and internal rotation, and the right in flexion and abduction. A radiograph of the pelvis three months after admission confirmed the suspected tuberculosis of the left hip joint with ankylosis, but the right hip joint itself was normal. The soft tissues surrounding both hip joints presented a most unusual appearance. There were extensive, ill-defined opacities, which appeared to be deposits of calcium (Fig. 1), situated in the adductors and flexors.

On orthopaedic advice no active measures were taken. The masses of ectopic calcifications or ossifications increased, leading to almost complete fixation of both hip joints in unfavourable positions. By now the child was well enough to stand and even walk with difficulty, but was unable to sit. He recovered from the meningitis, was transferred to an orthopaedic hospital, and he is still there, nearly three years after his original admission. By November, 1950, 10 months after admission, a massive bony bar was felt in the right thigh. A radiograph at this stage showed more clearly the extent and location of the lesions. On the right side the ossification involved the psoas major, the adductor longus, the adductor magnus and the pectineus (Fig. 2). The distribution on the left could not be so accurately determined because of the associated tuberculous arthritis with ankylosis.

Between February, 1951, and January, 1952, he underwent three operations. At the first the alignment of the left femur was corrected by an osteotomy. At the same time a mass of new bone was located, mainly in the iliacus, and was removed. It was separate from the femur. Unfortunately further new bone was again deposited and fixed the neck of the femur to the ilium.

The second operation was designed to remove the ectopic bone from the right thigh. Large masses of bone were removed from the adductors. After this considerable movement was possible in the hip joint, although deeper masses of bone in postero-medial relation to the hip joint were left in position. No benefit resulted from this operation, because further new bone was deposited and fixed the hip as much as ever. At the third and last operation further new bone was removed from the right thigh, but this procedure made things even worse. Although no new bone was now present in the more distal parts of the thigh, a dense scaffolding of new bone joined the whole of the neck of the femur to the pelvis (Fig. 3).

Although at present the child is in excellent physical and mental health, he is severely disabled; as he cannot sit, he walks with stiff hips and he has developed a scoliosis. There is no movement in the left hip and only some 15 to 20 degrees of flexion and no other movement in the right. In this child operative procedures probably did more harm than good.

In the three other survivors the results are not as serious. One of them is a 2-year-old hydrocephalic ament and ossification in the right adductors is only a curious incidental finding. In the third child metastatic ossification was first detected six months after the onset of meningitis and appeared to be confined to the tendon of the right iliopsoas (Fig. 4). It increased in density and thickness for a further six months (Fig. 5). during which time she remained unconscious. Since then she has made considerable improvement and now, at the age of $4 \frac{1}{2}$ years, although still considerably retarded, she can say a few words, she feeds herself and walks with assistance. At the end of September, 1952, there was some radiological evidence of resorption of the heterotopic bone 
(Fig. 6). Abduction of the thigh was restricted to some 10 degrees, but flexion and extension were not limited.

The fourth child is now a healthy normal boy of 7 . The first evidence of bilateral and symmetrical ossifications was found four months after he developed meningitis. The ossifications appeared to affect the iliopsoas tendons below the level of the pelvis and increased in extent for a further three months (Fig. 7). He recovered and started to walk. His gait was stiff at first, but it is now normal and he has no disability. The ossifications are now both shorter and more slender, suggesting spontaneous absorption of the new bone (Fig. 8).

The fifth child was a girl of 12 who died after a prolonged illness lasting for nearly two-and-a-half years. In the first 18 months she was fully conscious and in good general condition, but in January, 1951, she became much worse. At that time radiographs of the hips as well as of other joints were negative. These were taken because she complained of severe and widespread pain and stiffness in the joints, which were tender. Within a month she developed generalized rigidity, and was barely able to move. A month later bilateral ossifications developed in both iliopsoas muscles and tendons but nowhere else (Fig. 9). Following treatment with intrathecal tuberculin she made a substantial general improvement but the ossifications in the thighs increased greatly (Fig. 10), resulting in complete fixity of the hip joints, which lasted for several months, until her death. She died after a final relapse of meningitis, and at necropsy vast masses of ectopic bone were found both radiologically and by dissection (Fig. 11). The ectopic bone was mainly in the iliopsoas region. There was no evidence of tuberculous arthritis.

Biochemical estimations of serum calcium, phosphorus and phosphatase were normal in every case.

Histological examinations were performed on the specimens of bone removed at operations in the first child and on the necropsy specimens in the last. The presence of bone containing normal bone marrow was demonstrated (Figs. 12 and 13).

\section{Discussion}

Since the end of the 1914-18 war the syndrome of metastatic ossification following traumatic paraplegia due to spinal cord injuries has become well recognized. The first detailed account of the condition was given by Dejerine, Ceillier and Dejerine in 1919 on a large series of patients. They treated 160 patients with post-traumatic paraplegia and 78 of these $(48 \cdot 7 \%)$ developed metastatic ossifications. In all cases the new bone was deposited in the thigh, either around the hip joint or along the medial condyle of the femur. They never found lesions above the pelvis or below the knee and their observations on this point were confirmed by all subsequent writers on this subject. The joints themselves were not involved. They found no evidence of infection or of haemorrhage in the affected areas, and they found no calcification or ossification in the chronic pressure sores in these patients. Biopsy specimens of the ectopic ossifications proved the deposits to be normal bone.

Several confirmatory studies have been published but little new has been added to our knowledge. The incidence in some of the larger series (Miller and O'Neill, 1949) has not been as high as that of Dejerine's series. All writers agreed about the characteristic distribution of the lesions, which usually developed within a year after the spinal cord injury. The earliest appearance was usually unknown in the absence of serial radiological studies (Abramson and Kamberg, 1949; Geldmacher, 1925; Hanke, 1943; Heilbrun and Kuhn, 1947; Lüdeke, 1950; Miller and O'Neill, 1949; Soule, 1945; Soule and Stiff, 1949; Stanger, 1947).

Voss (1937) collected from the literature several single cases in which other diseases of the central nervous system were associated with metastatic ossification and added four cases of his own. Three of these followed cerebral haemorrhage. Some of the collected cases were of doubtful authenticity. More recently presumed cases of poliomyelitis were followed by widespread ossification of the soft tissues, involving the upper as well as the lower limbs (Drehmann, 1927; Costello and Brown, 1951 ; Freiberg, 1952). It is possible, however, that the illness, consisting of widespread and progressive muscle paralysis followed by ossification, was not due to the virus of poliomyelitis.

The aetiology of metastatic ossification is little understood. This is perhaps not surprising, considering that the exact biochemical mechanism of normal ossification has not yet been fully clarified (Best and Taylor, 1950). Almost all the writers quoted agreed that the biochemical studies of the serum were unhelpful, the figures for calcium, phosphorus and phosphatase being always normal. It is possible, however, that abnormalities might have been detected had estimations been carried out at a stage immediately preceding or at the beginning of the ossifications. Robison (1923) drew attention to the importance of phosphatase in the process of ossification. Wilkins, Regen and Carpenter (1935) found that in a case of progressive myositis ossificans biopsy specimens of muscles and fibrous tissue which were about to undergo ossification contained 800 to 1,600 times as much phosphatase as did normal muscle. They felt that this gross excess of phosphatase may lead to precipitation of calcium from normal serum, but it did not explain why normal cancellous bone should be formed and not amorphous calcification. Fibrous tissue within the muscles had the highest phosphatase content and this agreed with the histological observations of the 

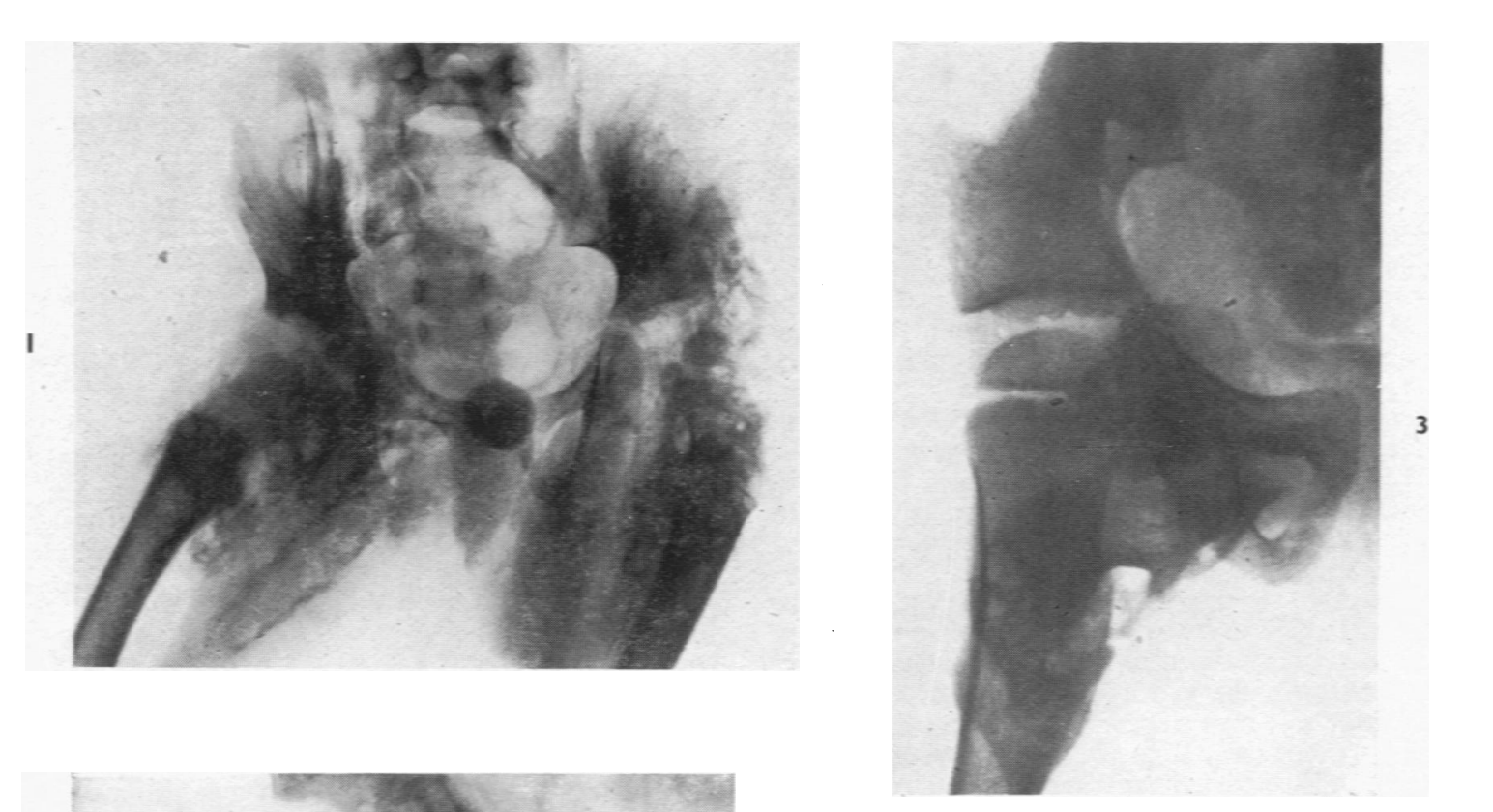

2

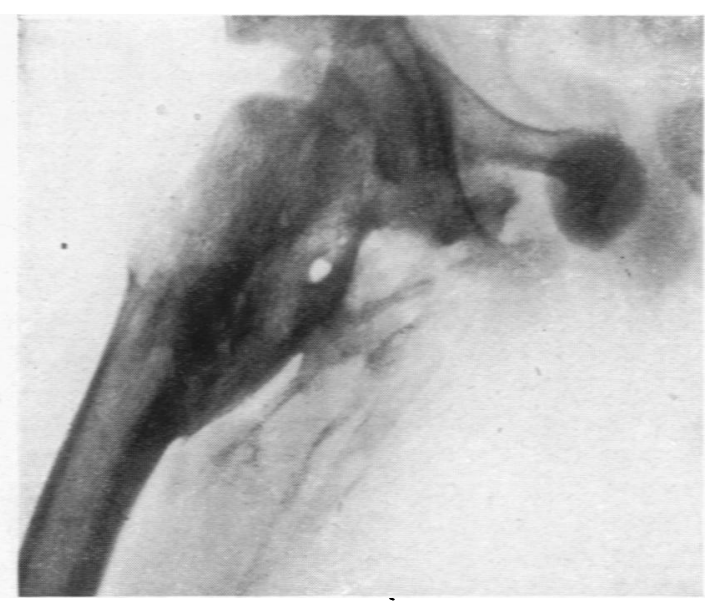

Frg. 1.-Case 1: extensive tuberculosis of left hip joint. Normal right hip joint. Diffuse bilateral soft tissue calcifications in adductors and flexors of both hip joints.

Fig. 2.-Case 1: right hip 10 months after admission. Ossification of adductors better defined.

Fig. 3. - Case 1: right hip 33 months after admission, following two operations for removal of ectopic bone. Dense scaffolding of new bone unites neck and head of the femur to the pelvis.

Frg. 4.-Case 3: right hip showing ill-defined ossification of iliopsoas tendon (six months after admission).
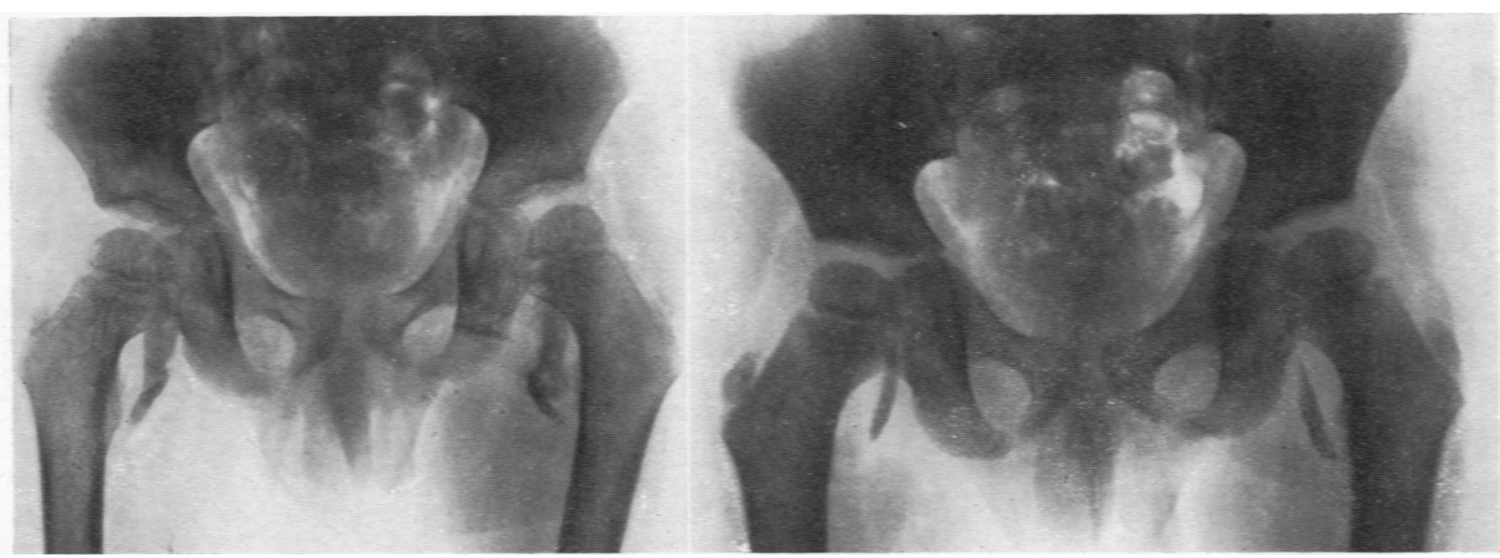


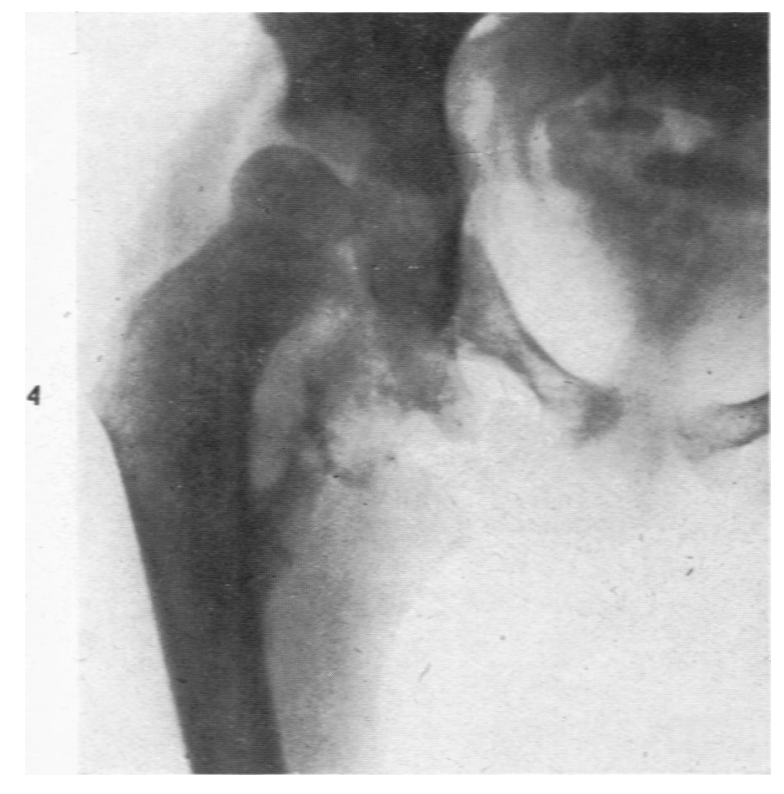

Fig. 5.-Case 3: six months later. Dense ossification of the right iliopsoas tendon.

Fig. 6. Case 3: further 14 months later showing spontaneous partial absorption of the ectopic bone at its proximal half.

Frg. 7.-Case 4: bilateral ossifications of the iliopsoas tendons.

Fig. 8.-Case 4: ossifications both shorter and narrower one year later. Spontaneous absorption.

Fig. $9 a$ and $b$. - Case 5 : both hips showing considerable ossification of iliopsoas tendons three months after onset of paraplegia.
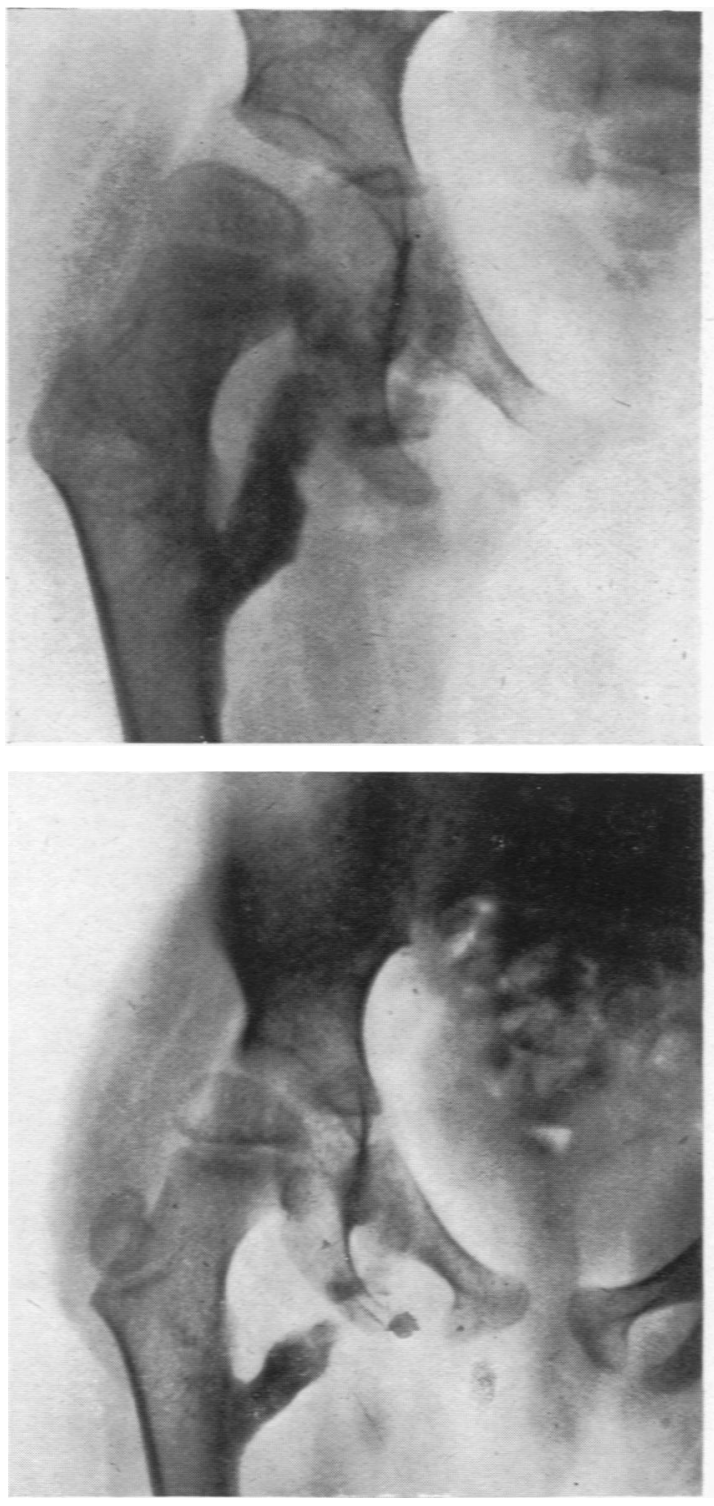

6

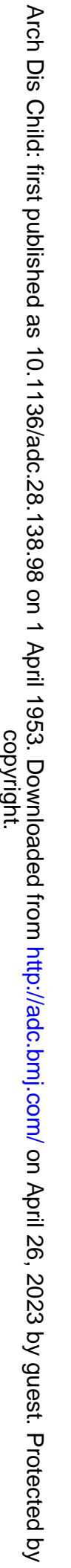




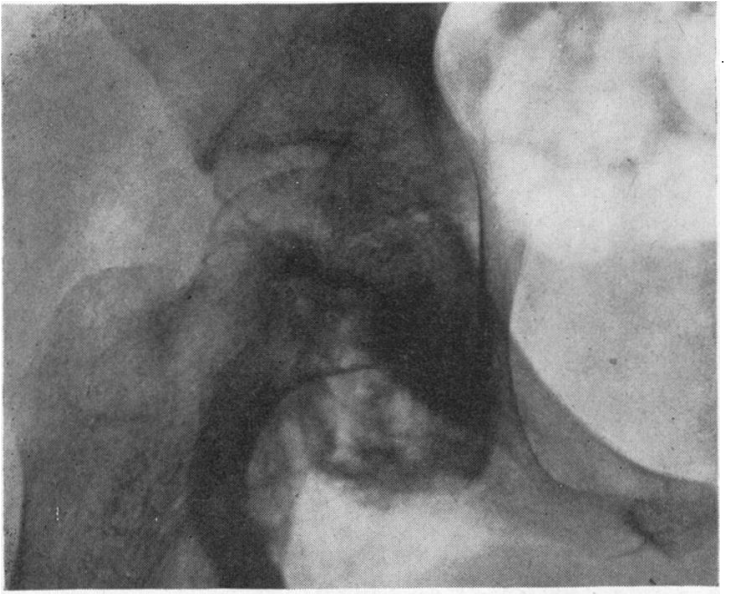

FIG. 10.

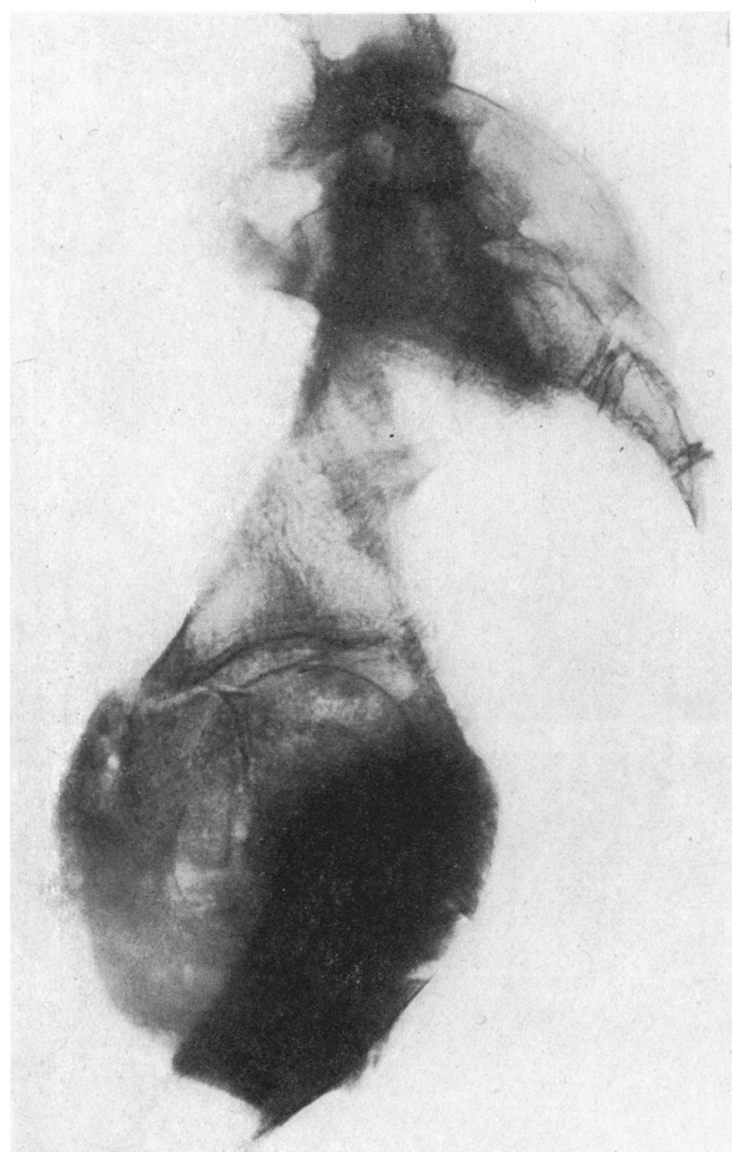

FIG. 11.

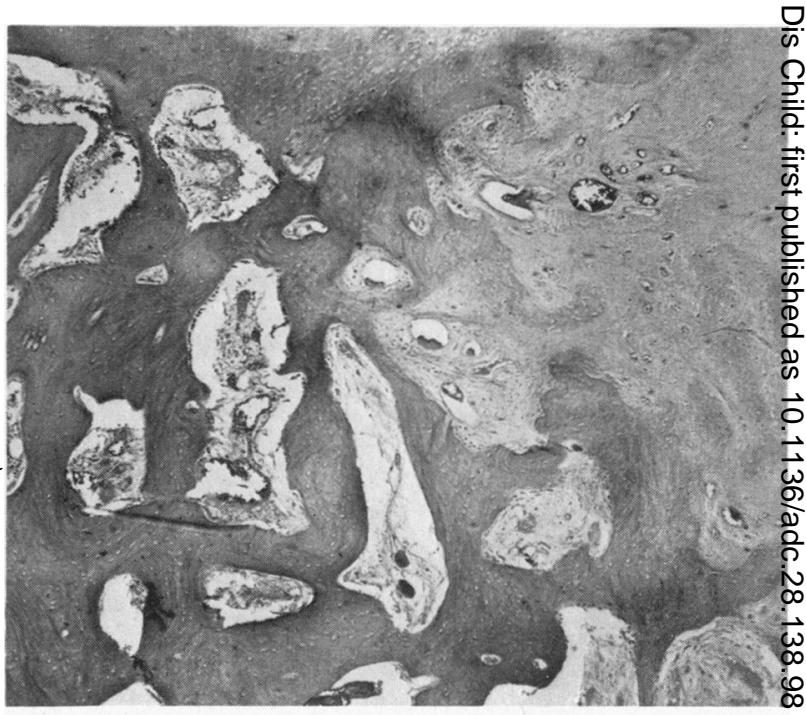

FIG. 12.

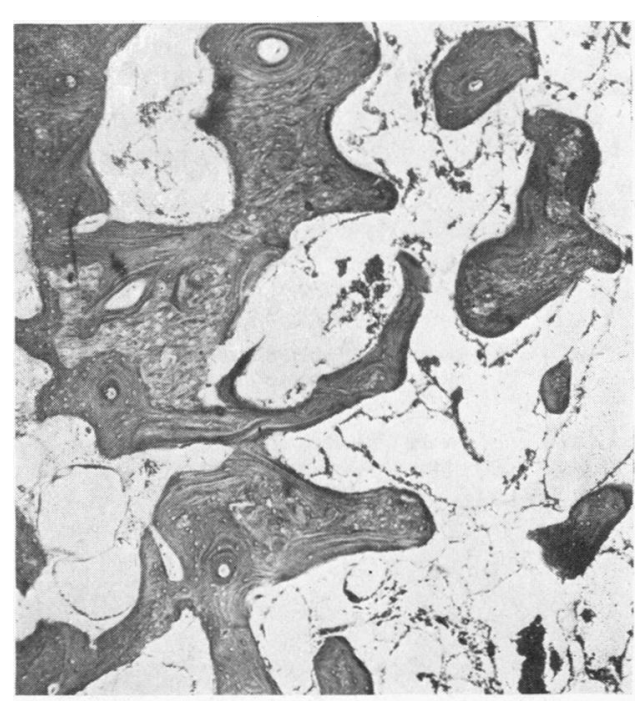

FIG. 13.

Fig. 10.-Case 5: right hip showing gross deposits of ectopic bone around the joint after a further period of three months

옥 
previously quoted workers that fascial planes, ligaments and tendons ossify, not the muscle tissue itself. According to Watson Jones and Roberts (1934) fibroblasts or any mesenchymal cells may dedifferentiate and become capable of laying down bone. Other factors mentioned as necessary for pathological ossification are decreased oxygenation and blood supply (Leriche and Policard, 1926: Watson Jones and Roberts, 1934), local tissue damage (Vaughan, Sosman and Kinney, 1947) and decreased local $\mathrm{CO}_{2}$ tension or increased alkalinity of the tissues (Wells, 1925).

Clinically, it seems that the factor necessary for the development of ectopic ossification is a spinal cord lesion with paraplegia in flexion, leading to muscle spasm and prolonged immobilization with consequent osteoporosis.

\section{Summary}

Ectopic ossification was demonstrated radiologically in five of 10 children who developed temporary paraplegia in flexion during streptomycin treatment of tuberculous meningitis and survived for more than three months. It was found two to six months after the onset of the paraplegia. In all cases the ossification affected the iliopsoas or the adductors of the thighs and their tendons below the level of the pelvis. The lesions were bilateral in three patients. They led to severe disability in two children by fixing the hip joints and to less severe symptoms in the others. Operative removal of the new bone in one child led to more extensive deposition of new bone and a worsening of his condition. In two conservatively treated patients there was subsequent radiological evidence of spontaneous absorption of new bone after recovery from meningitis.

The diagnosis was established radiologically in all patients and was confirmed at operation in one and at necropsy in another child. Histologically the ectopic tissue appeared to be normal bone with bone marrow.

The incidence and nature of neurogenic metastatic ossifications was reviewed. No previous instances in association with tuberculous meningitis have been found.

I wish to thank Professor R. S. Illingworth for his criticism, Dr. T. Lodge for the radiographs, Dr. J. L. Emery for the necropsy and histological findings, Mr. F. W. Holdsworth for permission to quote the operative findings in case 1 and Mr. A. Tunstill for the photographic work.

\section{REFERENCES}

Abramson, D. J. and Kamberg, S. (1949). J. Bone Jt Surg., 31 A, 275. Best, C. H. and Tavlor, N. B. (1950). The Physiological Basis of Medical Practice, 5th ed. pp. 827-830. London.

Costello, F. V and Brown, A (1951). J. Bone Jt Surg. 33 B, 594.

Dejerine, Mme., Ceillier, A. and Dejerine, Y. (1919). Rev. Neurol., Paris, 26, 399

Drehmann, G. (1927). Abstracted Zbl. ges. Neurol. Psychiat. (1928), 48. 686.

Freiberg, J. A. (1952). J. Bone Jt Surg., 34 A, 339.

Geldmacher, M (1925), Disch, Z Chir. 191, 180.

Hanke, H. (1943). Ibid., 258, 217.

Heilbrun, N. and Kuhn, W. G., Jr. (1947). Radiology, 48. 579.

Leriche, K. and Policard, A. (1926). Les problemes de la physiologie normale et pathologique de los. Paris.

Lüdeke, H. (1950). Fortschr. Röntgenstr. 73, 564

Millet, L. F and O'Neill, C. J. (1949). J. Bone Jt Surg., 31 A, 283.

Robicon R (1923), Biochem. J., 17, 286.

Soule, A. B., Jr. (1945). J. Neurosurg., 2485

- and Stiff, D. W. S. (1949). Bull. ' $L$ 'S. Army med. Dep., 9, 1018 Stanger, J. K. (1947). J. Bone Jt Surg., 29, 107.

Vaughan, J. H., Sosman, M. C. and Kinney, T. D. (1947). Amer. J. Roentgenol, $58,33$.

Voss, H. (1937). Fortschr. Röntgenstr., 55, 423.

Wat, 4 .

Welk, H. G. (1925). Chemical Pathology, 5th ed., p. 486. Philadelphia.

Wilkins, W. E., Regen, E. M. and Carpenter, G. K. (1935). Amer. J. Dis. Child., 49, 1219. 